\title{
Fatigue Characteristics of High Glass Content Sheet Molding Compound (SMC) Materials
}

\author{
P. K. MALLICK* \\ Department of Mechanical Engineering \\ The University of Michigan-Dearborn \\ Dearborn, Michigan 48128
}

\begin{abstract}
Static and fatigue properties of high glass content sheet molding compound (SMC) materials were studied at various temperatures. It was shown that the matrix plays an important role in both fatigue characteristics and failure mechanisms of such randomly oriented short fiber composites. Specifically, vinyl ester matrix shows better fatigue properties and postfatigue performance than the polyester system considered here.
\end{abstract}

\section{INTRODUCTION}

$\mathrm{W}$ ith the introduction of high glass content, high strength sheet molding compounds (HSMC) in recent years, fiber reinforced plastics are being considered in many structural applications in automotive and other non-aerospace industries. This class of material is basically a modified SMC, containing 50-65 percent by weight of randomly oriented chopped glass fiber strands and little or no filler whereas conventional SMC contains only 25-30 percent glass fiber and 30-40 percent filler, usually calcium carbonate. HSMC is compounded and prepared in a standard SMC machine and compression molded at pressures ranging up to 3,000 psi. Because of their relatively high strength and modulus (which arise from higher glass content) and ease of molding, complex structural shapes can now be designed and manufactured from these materials. Consequently, there is a great need for characterizing the mechanical and physical properties of HSMCs and developing design guidelines. However, most of the studies dealing with such materials have involved formulation and compounding $(1,2)$, static mechanical properties (3) and recently, evaluation of curing characteristics (4). Very litthe attention has been given to fatigue properties even though some of the applications under consideration may be subjected to cyclic loading.

In this paper, static and fatigue properties of high glass content SMC materials with three different matrix systems are reported. In addition, mechanisms of failure are also presented.

\section{MATERIALS}

The principal materials investigated in this study are polyester (isophthalic) and vinyl ester HMSCs with a nominal glass fiber content of $60-65$ percent by weight. In addition, some tests were al so performed on an epoxy molding compound which has a similar glass fiber con-

*Formerly with Plastics Development and Applications Office, Ford Motor Co. Detroit, Michigan. tent; however, in this case, the nominal fiber length is $1 / 2$ in. compared to $1 \mathrm{in}$. for the polyester and vinyl ester systems. None of the systems has any filler in it. All these materials are commercially available and are being considered for various structural applications by the automotive industry.

The compounds were molded into flat plaques in laboratory size presses at or near a mold temperature of $300^{\circ} \mathrm{F}$. Test specimens were first saw cut from the molded plaques and then polished on a sand belt to smoothen the edges. All specimens were approximately half-inch wide and at least $5 \mathrm{in}$. long.

\section{EXPERIMENTAL PROCEDURE}

Fatigue tests were performed on an MTS servohydraulic machine with a three-point constrained flexure fixture. A schematic of the fixture is shown in Fig. 1 in which the specimen is clamped at the ends and loaded at the center of the span. In this mode of loading, equal maximum stress occurs under the center loading point and near the end constraints. Fatigue specimens were subjected to completely reversed, sinusoidal al ternating stresses (tension-compression, $R=-1$ ) at $300 \mathrm{cpm}$. The stroke of the actuator, set to provide a predetermined initial peak load, was maintained at a constant level during the test. At intervals, cycling frequency was reduced to $3 \mathrm{cpm}$ and load-displacement curves were recorded. Dvnamic modulus values were obtained from the initial slopes of these curves. Failure was defined as a 15-20 percent drop in the dynamic modulus from its value measured between 1-10 cycles. At the end of the fatigue tests, each specimen was tested in static flexure to measure its residual strength. Fatigue tests were run in an envirommental chamber at RT, 130, 220, and $320^{\circ} \mathrm{F}$.

All static tests, including those after fatigue loading, were performed on a simply supported three-point flex fixture on an Instron universal testing machine. Elevated tempcrature static tests were run in the Instron 

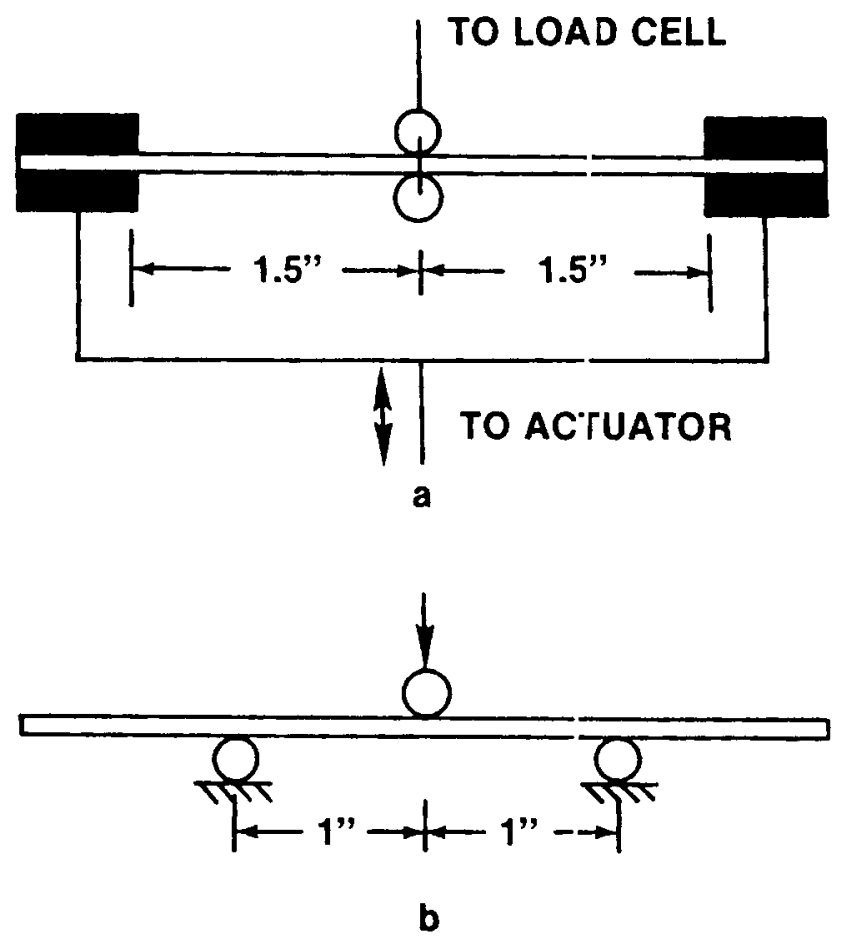

Fig. 1. Schematic of experimental set-up-(a) fatigue test (b) static flexture test after fatigue.

environmental chamber. A two-inch span was used in all these tests. Thus the damaged ends of the fatigue specimens near the clamps were excluded from the postfatigue static test area.

\section{RESULTS}

\section{Static Properties}

Room temperature static flexural oroperties of high glass content materials (HS.MC) are presented in Table 1. For comparison, typical values for conventional SMC are also included. Higher values for the present materials are direct results of their higher ylass fiber content. The load-deflection curves are initially linear, but, at stresses between 35-50 percent of the ultimate values they deviate from linearity indicating; the occurrence of some irreversible damage in the material. Generally, this damage takes the form of "microcracks" or "crazes", possibly a result of fiber-matrix debronding $(5,7)$. Final failure takes place in a step-wise fashion starting with a failure on the tension surface followeci by delaminations.

Figures 2 and 3 show the percent retention of flexural strength and modulus as a function of test temperature. As expected, both strength and modulus decrease with increasing temperature. Even thongh this reduction

Table 1. Room Temperature Static Flexul'al Properties of High Glass Content SMC Materials

\begin{tabular}{lccc}
\hline $\begin{array}{c}\text { Matrix } \\
\text { material }\end{array}$ & $\begin{array}{c}\text { Nominal } \\
\text { glass } \\
\text { content } \\
\text { (\% wt) }\end{array}$ & $\begin{array}{c}\text { Flextural } \\
\text { strength } \\
\text { (f si) }\end{array}$ & $\begin{array}{c}\text { Flextural } \\
\text { modulus } \\
\text { (10 psi) }\end{array}$ \\
\hline Polyester $^{\star}$ & 30 & 35000 & 1.8 \\
Polyester $_{\text {Vinyl ester }}$ & 65 & 55.660 & 2.30 \\
Epoxy & 59 & 43,200 & 1.92 \\
\hline
\end{tabular}

"Conventional SMC.

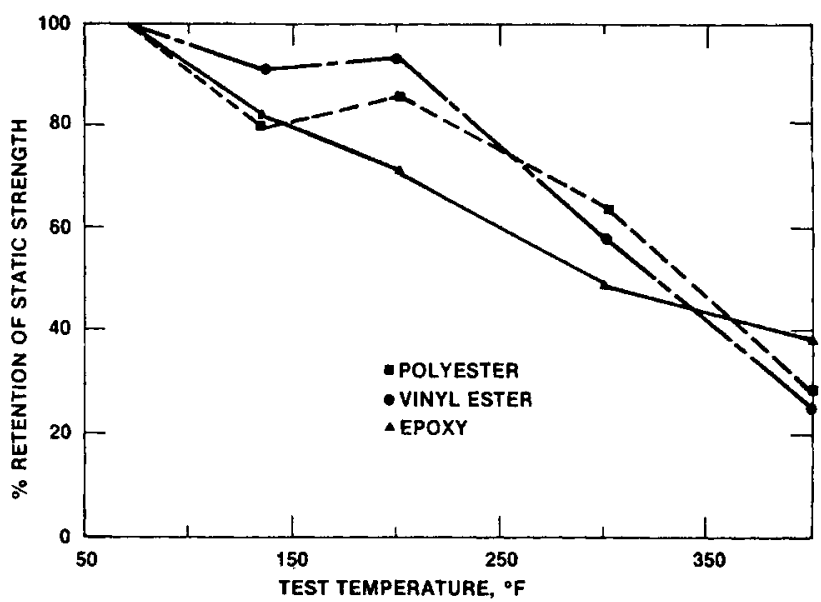

Fig. 2. Retention of static ultimate strength in flexure as a function of test temperature.

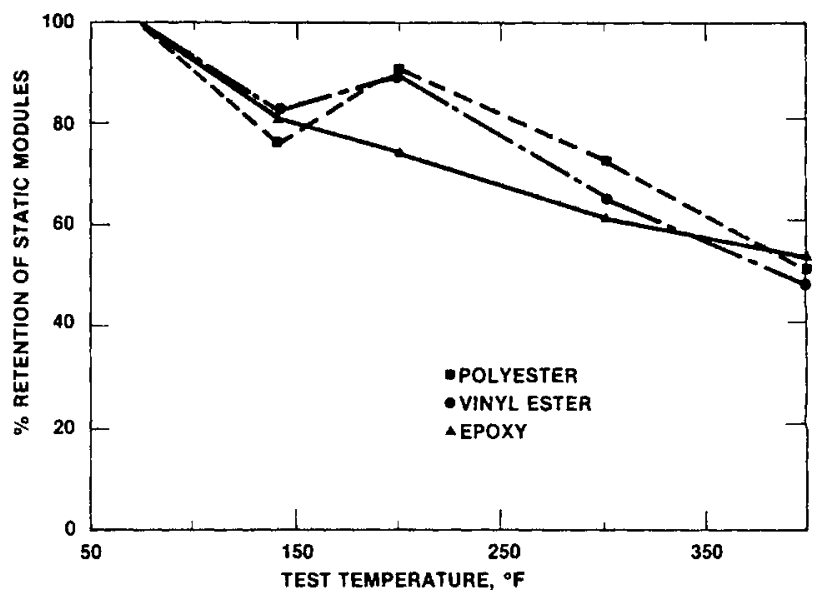

Fig. 3. Retention of static modulus in flexure as a function of test temperatures.

is mostly a result of softening of the matrix resin, a clear superiority of one system over another cannot be established from these figures. However, for design purposes where short-term high temperature is encountered, these diagrams will be helpful.

\section{Fatigue Properties}

Definition of Failure. Since materials under consideration fail in a progressive mamer through gradual softening as the test progresses, a clear definition of failure is not possible. Therefore, a $15-20$ percent drop in modulus from its value near the 10th cycle was arbitrarily selected as a criterion of failure. Figure 4 is one such plot of percent drop in modulus vs number of cycles. It can be seen here that the vinyl ester composites show a lesser drop in modulus than the polyester composites for an equal number of fatigue cycles.

The loss in modulus is, in general, a result of the appearance and growth of damage zones at the areas of maximum stresses. The damage is in the form of microcracks which first appear on the outer surface, then extends into the interior of the specimens. The cracks are, in most cases, oriented in a direction nomal to the principal stress, but do not always cover the whole width of the specimen. As shown in Fig. 5a, the intensity of the 


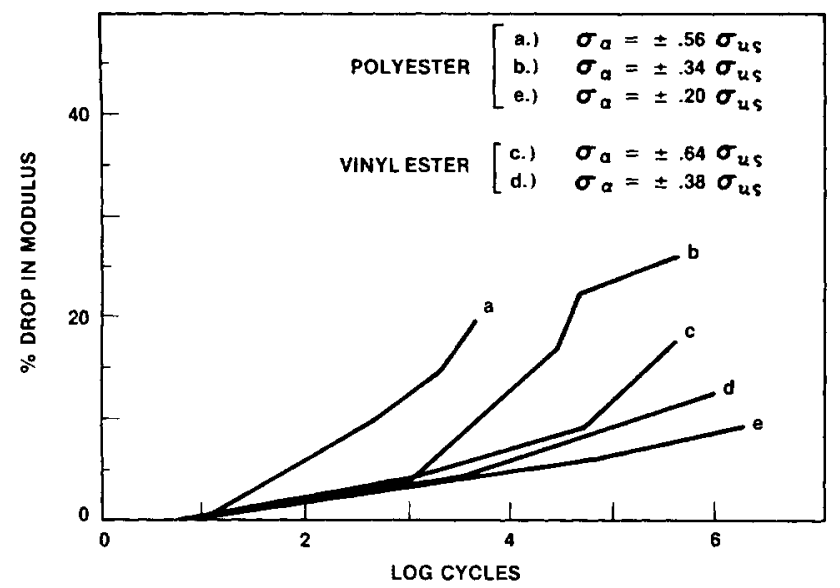

Fig. 4. Drop in modulus vs number of cycles during fatigue at $130^{\circ} \mathrm{F}$.

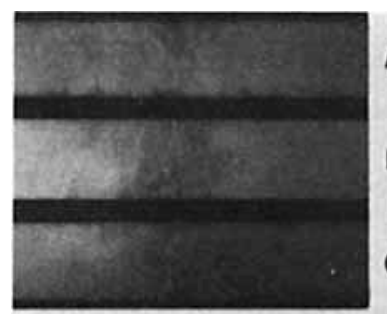

POLYESTER

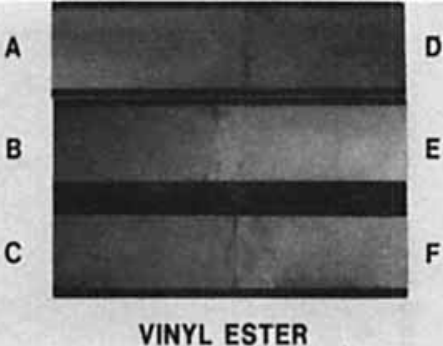

Fig. 5. (a) Fatigue damage in polyester specimens at $\pm 15,000$ psi with (A) 2,000 (B) 40,000 and (C) 367,000 cycles. (b) Fatigue damage in vinyl ester specimens-(D) 895,000 cycles at +15.000 psi, (E) 15,000 cycles, and (F) 376,000 cycles at $\pm 20,000$ psi.

damage zone, indicated by the number of cracks, increases with number of cycles. Figure $5 b$ shows that for equal number of cycles, at the same stress level, there are more microcracks on the polyester specimen than on the vinyl ester specimen.

Fatigue Life. Figure 6 shows a $\mathrm{S}-\mathrm{N}$ plot of fatigue stress level vs number of cycles to failure for polyester and vinyl ester composites at $130^{\circ} \mathrm{F}$. Within the range of cycles investigated, these materials do not exhibit any fatigue limit and the number of cycles to failure gradually increases with decreasing stress level. However, at $10^{6}$ cycles, the endurance limit of vinyl ester composites is approximately 60 percent higher than the polvester composites.

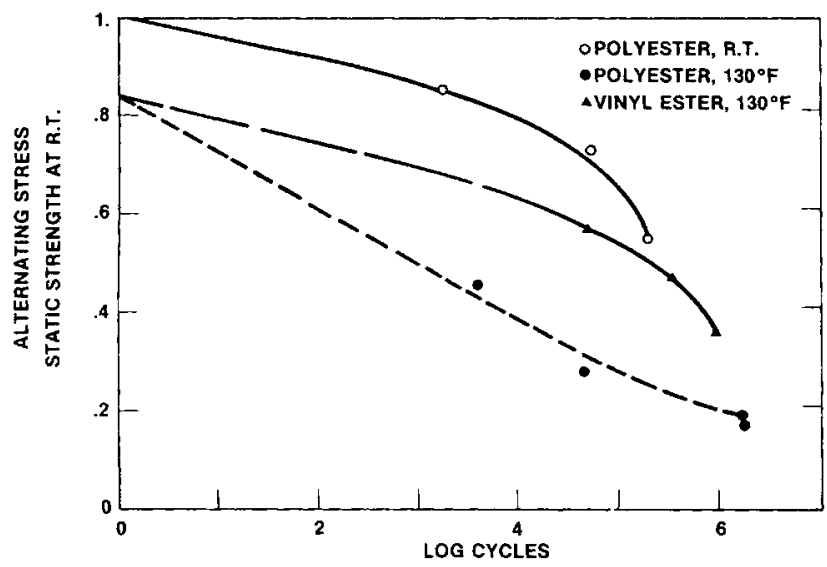

Fig. 6. Fatigue stress vs number of cycles in reversed flexural fatiguc.
Room temperature data for polyester composites are also plotted in Fig. 6 to indicate the effect of temperature on fatigue life. Table 2 lists the fatigue properties for three different matrices at or near 200,000 cycles at a test temperature of $220^{\circ} \mathrm{F}$. Although based on limited data, it indicates that vinyl esters have superior fatigue performance than polyesters and nearly equal to the epoxy system considered. It should be noted, though, that the epoxy system had significantly shorter fibers than the other two systems.

Post-Fatigue Performance. After testing for a certain number of cycles, middle sections of some of the fatigued specimens were subjected to static Hexure to determine the residual strength of the material. These values are presented in Table 3. In general, residual static strength decreases with increasing number of $\mathrm{cy}$ cles in contrast to some high performance unidirectional composites where minimal loss in static strength is often observed (6). The microcracks formed on the surface of the HSMC specimens during fatigue loading act as sharp notches. Some of these microcracks extend and/or join to form a critical crack, thereby causing a premature failure at a lower static load. Harris, et al. (7) reported a similar result on dough molding compound (DMC) materials where a large and rapid drop in strength was observed after 100-1000 cycles at cyclic stresses of about 75 percent of the ultimate strength of the material. At lower stresses, however, the tests were carried to only 1,000 cycles; even then, a loss in static strength was observed, but only after an initial increase at about 10 cycles.

Another observation to be made from Table 3 is that vinyl ester material retains more of its static strength than polvester after fatigue. This is in accordance with the fact that there were more fatigne microcracking on polyester specimens than the vinyl ester ones.

\section{DISCUSSION}

From the data presented, it is evident that specimens with vinyl ester resin show better resistance to fatigue than those with polyester. The reason for the difference can be found in the intensity of microcracks that form during cycling on the surfaces of these two different resins. The microcracks are probably results of both matrix cracking and failure of fiber-matrix interfacial bonds (5).

Since random fiber composites are not as much fiber dependent as unidirectional composites, the properties of the matrix resin and/or fiber-matrix interface are expected to play a major role in determining the mechanical properties of such materials. Vinyl ester resins have higher tensile strength and strain-to-failure than polyester. In addition, the secondary hydroxyl group in the vinyl ester chain provides a site for hydrogen bonding with a similar group on the surface of giass fibers, resulting in good wet-out and adhesion to fibers (8). The isophtalic polvester chain does not contain any such hydroxyl group and therefore, adhesion and wet-out can be promoted only through the binder on the glass surface. Thus vinyl ester resins would probably have a higher resistance to debonding and matrix cracking than 
Table 2. Fatigue Properties of High Glass Content SMC at $220^{\circ} \mathrm{F}$

\begin{tabular}{|c|c|c|c|c|c|c|}
\hline \multirow[b]{2}{*}{$\begin{array}{c}\text { Matrix } \\
\text { material }\end{array}$} & \multirow[b]{2}{*}{$\begin{array}{c}\text { Stress } \\
\text { level }\end{array}$} & \multirow{2}{*}{$\begin{array}{l}\text { Percent } \\
\text { UTS } \\
\text { a) } 220^{\circ} \mathrm{F}\end{array}$} & \multirow[b]{2}{*}{$\begin{array}{l}\text { No of } \\
\text { cycles }\end{array}$} & \multirow{2}{*}{$\begin{array}{l}\text { Percent } \\
\text { drop } \\
\text { in modulus }\end{array}$} & \multicolumn{2}{|c|}{$\begin{array}{l}\text { Residual } \\
\text { properties }\end{array}$} \\
\hline & & & & & $\begin{array}{l}\text { Strength } \\
\text { (psi) }\end{array}$ & $\begin{array}{c}\text { Modulus } \\
\left(10^{\prime i} \text { psi) }\right.\end{array}$ \\
\hline Polyester & 9,000 & 18.8 & 175,000 & 12.7 & - & - \\
\hline Vinyl ester & $\begin{array}{l}10,000 \\
12,500 \\
15,000\end{array}$ & $\begin{array}{l}25 \\
31 \\
37\end{array}$ & $\begin{array}{l}201,260 \\
200,000 \\
210,000\end{array}$ & $\begin{array}{c}5 \\
10.9 \\
10.6\end{array}$ & $\begin{array}{l}41,620 \\
35,380 \\
41,880\end{array}$ & $\begin{array}{l}2.02 \\
1.99 \\
2.205\end{array}$ \\
\hline Epoxy & $\begin{array}{l}10,000 \\
12,500 \\
15,000\end{array}$ & $\begin{array}{l}21.7 \\
27 \\
32.5\end{array}$ & $\begin{array}{l}202,150 \\
201,720 \\
200,000\end{array}$ & $\begin{array}{c}0 \\
11.2 \\
20.1\end{array}$ & $\begin{array}{l}56,960 \\
50,390 \\
36,850\end{array}$ & $\begin{array}{l}1.97 \\
1.94 \\
1.47\end{array}$ \\
\hline
\end{tabular}

Table 3. Residual Strength at Room Temperature after Fatigue

\begin{tabular}{|c|c|c|c|c|c|c|}
\hline $\begin{array}{c}\text { Test } \\
\text { temp (T) } \\
\left({ }^{\circ} F\right)\end{array}$ & $\begin{array}{c}\text { Matrix } \\
\text { material }\end{array}$ & $\begin{array}{c}\sigma a \\
(p s i)\end{array}$ & $\begin{array}{c}\text { Percent } \\
\text { UTS } \\
\text { at T }\end{array}$ & $\begin{array}{c}N \\
\text { (cycles) }\end{array}$ & $\begin{array}{l}\text { oRes } \\
\text { (psi) }\end{array}$ & $\frac{\sigma \text { Res }}{\sigma \text { ult }}$ \\
\hline \multirow[t]{2}{*}{130} & Polyester & $\begin{array}{r}9,000 \\
10,000 \\
12,500 \\
15,000 \\
15, C 00 \\
15, C 00 \\
15, C 00 \\
20, C .00 \\
25,(100\end{array}$ & $\begin{array}{l}20 \\
22.5 \\
28 \\
34 \\
34 \\
34 \\
34 \\
45 \\
56\end{array}$ & $\begin{array}{c}1.72 \times 10^{6} \\
1.63 \times 10^{6} \\
1.30 \times 10^{6} \\
2,000 \\
18,000 \\
48,000 \\
367,000 \\
40,000 \\
4,110\end{array}$ & $\begin{array}{l}39,010 \\
57,640 \\
40,710 \\
53,290 \\
44,850 \\
32,390 \\
36,900 \\
35,990 \\
36,460\end{array}$ & $\begin{array}{l}0.70 \\
1.03 \\
0.73 \\
0.96 \\
0.80 \\
0.58 \\
0.67 \\
0.65\end{array}$ \\
\hline & Vinyl ester & $\begin{array}{l}15,(100 \\
20,(100 \\
20,(100 \\
20,(100 \\
25,(100 \\
30,1100\end{array}$ & $\begin{array}{l}38 \\
51 \\
51 \\
51 \\
64 \\
76\end{array}$ & $\begin{array}{r}895,000 \\
15,000 \\
55,020 \\
376,000 \\
40,000 \\
10,000\end{array}$ & $\begin{array}{l}38,660 \\
42,940 \\
44,090 \\
33,660 \\
39,280 \\
40,160\end{array}$ & $\begin{array}{l}0.89 \\
1.99 \\
1.02 \\
0.78 \\
0.91 \\
0.93\end{array}$ \\
\hline \multirow[t]{3}{*}{320} & Polyester & $\begin{array}{l}9,1500 \\
9,1000\end{array}$ & $\begin{array}{l}25 \\
25\end{array}$ & $\begin{array}{l}200,400 \\
438,000\end{array}$ & $\begin{array}{l}47,800 \\
42,670\end{array}$ & $\begin{array}{l}0.88 \\
0.77\end{array}$ \\
\hline & Vinyl ester & 9,100 & 36 & 306,890 & 42,440 & 0.98 \\
\hline & Epoxy & 9,300 & 28 & 410,000 & 54,950 & 0.85 \\
\hline
\end{tabular}

polyesters. Pires et al found evidence of better adhesion with vinyl esters in their work on fiber-matrix interaction effects on fracture toughness on structural composites (9).

\section{CONCLUSION}

Based on the limited experimental obervations presented, following conclusions can be made regarding the fatigue characteristics of high gass content SMC materials:

- Up to $10^{6}$ cycles, no fatigue limit could be observed with any of the two systems considered.

- In random fiber composites, 1 atrix plays an important role in determining the fatigue characteristics of the material. More spec fically, vinyl ester matrix has shown fatigue properties which are better than polyester and may be equivalent to the epoxy system considered here.

- Fatigue damage in these materials is manifested by a cluster of microcracks, whose severity depends on the choice of matrix. As a result of such microcracks, the static strength of the material is reduced significantly. The magnitude of damage depends on the fatigue stress level, test tempera- ture and number of cycles.

- At low fatigue stress level (30-50 percent of the UTS), the fatigue damage is progressive, rather than catastrophic.

\section{ACKNOWLEDGMENT}

The author wishes to thank Dr. S. Newman of the Ford Motor Company for his valuable suggestions during the preparation of this paper.

\section{REFERENCES}

1. J. Maaghul and E. J. Potkanowicz, 31 st Annual Tech. Confer., SPI, 7-C (1976).

2. R. S. Sapp, Reinforced Thermoset Press Molding Committee Mtg., SPI (1976).

3. R. E. Thomas and J. H. Enos, 33rd Annual Tech. Confer, SPI (1978).

4. P. K. Mallick and N. Raghupathi, Symposium for Thermosets, SPE RETEC (1978).

5. M. J. Owen, Compos. Mater., 5, 313 (1974).

6. J. B. Sturgeon, 28th Annual Tech. Confer., SPI, 12-B (1973).

7. B. Harris, A. O. Ankara, D. Cawthome and S. M. T. Bye, Composites, 185 (1977).

8. Derakane Vinyl Ester Resins for Corrosion Resistance, Dow Chemical Co. (1975).

9. D. G. Pires, et al., AMMRC CTR 75-15 (July 1975). 